\title{
Respiratory infections due to Streptococcus pneumoniae and the influenza virus in South Africans undertaking the Hajj
}

\author{
Salim Parker ${ }^{a *}$, Anwar Ahmed Hoosen $^{b, c}$, Charles Feldman $^{d}$, Amgad Gamil $^{\mathrm{e}}$, Jerusha Naidoo ${ }^{\mathrm{f}}$ and Shameema Khan ${ }^{\mathrm{g}}$ \\ ${ }^{a}$ Dee Bee Centre, Elsies River, South Africa \\ ${ }^{b}$ Department of Medical Microbiology, University of the Free State, Bloemfontein, South Africa \\ 'Microbiology Laboratory, Universitas Academic Laboratory, National Health Laboratory Service, Bloemfontein, South Africa \\ ${ }^{d}$ Division of Pulmonology, Department of Internal Medicine, Charlotte Maxeke Johannesburg Academic Hospital and Faculty of Health \\ Sciences, University of the Witwatersrand, Johannesburg, South Africa \\ ${ }^{e}$ Pfizer Global Medical Development and Scientific/Clinical Affairs, Vaccines, Pfizer Inc, Dubai, UAE \\ ${ }^{f}$ Pfizer Global Medical Development and Scientific/Clinical Affairs, Vaccines, Pfizer Inc, Johannesburg, South Africa \\ ${ }^{9}$ Ampath, Westridge, Durban, South Africa \\ *Corresponding author, email: salimparker@yahoo.com \\ Check for updates \\ The Hajj is the largest annual mass gathering on Earth. Respiratory infections are one of the leading causes of disease and \\ hospitalisation during the pilgrimage, with pneumonia and influenza most common among these infections despite the \\ availability of prophylactic vaccines. In fact, immunisation against influenza and pneumococcal disease is currently not a \\ requirement for South African pilgrims entering Saudi Arabia. This review examines the burden of respiratory infections \\ during the Hajj, particularly pneumonia and influenza, with a focus on pilgrims from South Africa. Although the number of \\ South African pilgrims attending the Hajj has been capped at 2000 since 2013, > 30000 South Africans perform the minor \\ Umrah pilgrimage annually. Understanding the aetiology of disease in this group could have implications for medical \\ resourcing during the Hajj.
}

Keywords: Hajj, influenza virus, pilgrims, pneumonia, respiratory infection, Streptococcus pneumoniae, South Africa

\section{Introduction}

The Hajj is a compulsory five-day pilgrimage to Makkah, Saudi Arabia, that is undertaken by all able-bodied Muslims with financial means. ${ }^{1,2}$ Whereas pilgrims typically visit both Makkah and Madinah, by strict definition only travel to Makkah is classified as the Hajj. Similar to the Hajj, the Umrah is a pilgrimage to Makkah, but it can be made at any time of year and spans a shorter period.

The Hajj is the largest annual mass gathering on Earth, with the 2012 and 2013 Hajj combined attracting more than 5 million pilgrims representing more than 184 countries. $^{2}$ During the Hajj a large number of geographically diverse pilgrims, many elderly with underlying medical conditions, are brought together in close proximity to perform prescribed religious rites. Although the duration of the Hajj is 5 days, most pilgrims remain in Saudi Arabia for a number of weeks. ${ }^{2,3}$

Intense congestion of people, extreme heat and diverse geographic origins of pilgrims together contribute to the spread of infectious diseases before, during and following the Hajj. ${ }^{1,2}$ Further complicating disease management, the Hajj follows the lunar calendar thereby beginning 10 days earlier every year and resulting in a continual shifting of seasons. $^{2,4}$

The coordinated mass movement of pilgrims requires some of the world's most intensively planned public health and infection control protocols. Prolonged stays in the cities of Makkah and Madinah and constant intermingling of pilgrims are particularly conducive to airborne disease transmission. Infectious diseases acquired during the Hajj can cause local and global ramifications as pilgrims travel home, exemplified by the 2003 Neisseria meningitidis serogroup W135 outbreak in Burkina Faso. ${ }^{5}$ Respiratory infections resulting from viral and bacterial pathogens are common during the Hajj, with influenza being one of the most frequently encountered vaccine-preventable diseases. ${ }^{6-8}$ Pneumococcal infections, which are common causes of hospitalisations among pilgrims, $^{9}$ are also potentially preventable by vaccination.

\section{Demographics of South African pilgrims}

In 2006, the South African Hajj quota was fixed at 5000 pilgrims ${ }^{3}$; by 2013 this number had been reduced to $2000 .^{10}$ Quotas were expected to increase after renovation of the Holy Mosque. ${ }^{11}$ More than 30000 South Africans perform the minor Umrah pilgrimage annually; in 2014, approximately 34000 Umrah visas were issued and approximately 40000 were expected to be issued in 2015 (Personal communication, Salim Parker, Dee Bee Centre; February 13, 2017).

In December 2007, the percentage of South African Hajj pilgrims $\geq 50$ years of age was $40.4 \%$ (1 995 of 4928 ), ${ }^{3}$ a proportion that has remained relatively constant in subsequent years (Personal communication, Salim Parker, Dee Bee Centre; February 13 , 2017). Many of the pilgrims $\geq 50$ years of age had underlying comorbidities more common in older adults, ${ }^{12}$ such as cardiovascular disease, pulmonary disease and diabetes mellitus. Importantly, adults $\geq 50$ years of age and adults with comorbid conditions are at increased risk for developing communityacquired pneumonia (CAP) and invasive pneumococcal disease (IPD). ${ }^{13,14}$ 


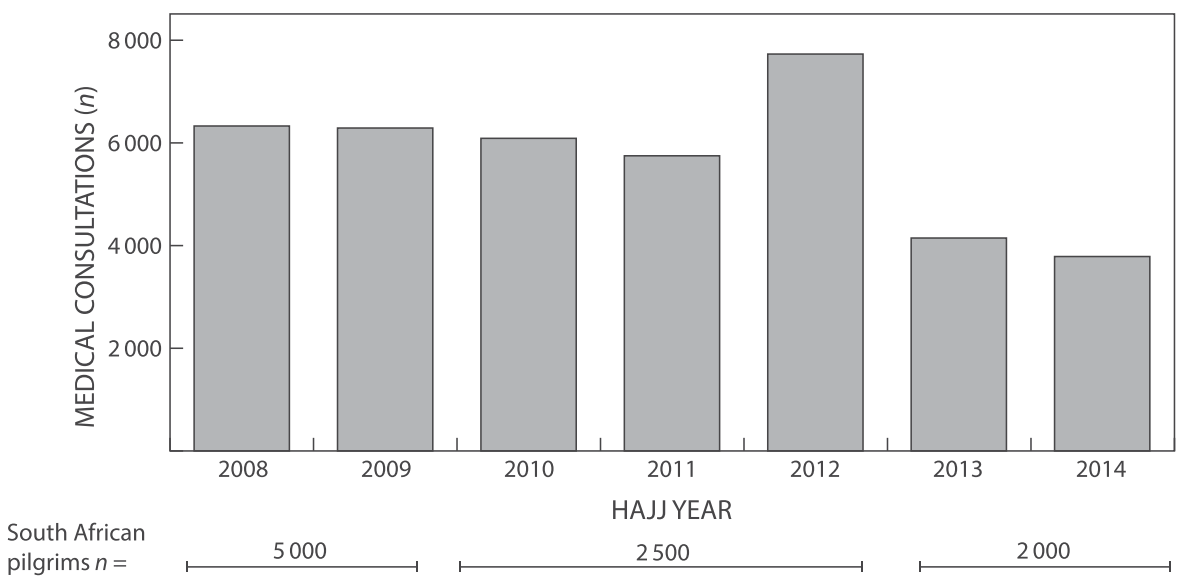

Figure 1: Number of medical consultations among South African Hajj pilgrims 2008-2014.

\section{Medical treatment during the Hajj}

A high percentage of pilgrims attending the Hajj require medical consultations during their stay in Saudi Arabia, with approximately 472000 pilgrims receiving medical attention during the 2014 Hajj. ${ }^{15}$ Of these, 329000 received treatment at the holy sites, 111000 utilised outpatient clinics, 28000 were treated in the emergency department, and 3700 had inpatient care. Emergency and field medicine teams attended 19000 pilgrims. ${ }^{15}$

Between 2008 and 2014, approximately 34181 medical consultations were required for South African pilgrims attending the Hajj (Personal communication, Salim Parker, Dee Bee Centre; February 13, 2017; Figure 1). Among the 2000 South African pilgrims attending the 2014 Hajj, there were 3780 medical consultations logged by the South African Hajj and Umrah Council (SAHUC) clinics located in Makkah, Azizia, Madinah and Meena/Arafat (Table 1). A slightly higher percentage of females sought medical consultations and the highest number occurred in Azizia, which was visited toward the end of the Hajj. When data from the cities of Makkah, Azizia and Madinah were combined, pilgrims from the Western Cape region accounted for the largest proportion of medical consultations.
Outside of general sequelae associated with the arduous nature of the pilgrimage (e.g. generalised body pain, dehydration, fatigue, nausea), respiratory conditions accounted for the highest number of medical consultations among South Africans attending the 2014 Hajj (Table 2).

\section{Burden of respiratory infections during the Hajj}

Respiratory infections are common during the Hajj and transmission has been well documented. ${ }^{9,16-20}$ Respiratory tract infections have also been the most frequently reported disease among South African pilgrims returning from the Hajj. ${ }^{21}$ Overall, an estimated $33 \%$ of Hajj pilgrims develop a respiratory infection characterised by cough, sore throat, fever, rhinorrhoea, malaise and sputum production. ${ }^{16}$ Pneumonia is among the most frequently reported respiratory infections and is the most common cause of hospital admission and medical consultations during the Hajj. For example, a prospective study conducted in two hospitals during the 2002 Hajj identified respiratory infections as the leading cause of hospital admission among pilgrims (57\%); the majority of these admissions were due to pneumonia. ${ }^{9}$

Table 1: Demographics of South African pilgrims requiring medical consultations during the 2014 Hajj

\begin{tabular}{|l|c|c|c|c|}
\hline & \multicolumn{3}{|c|}{ Medical consultations by city for all South African pilgrims $(N=2000)$} \\
\hline \multicolumn{1}{|c|}{ Demographics } & Makkah & Azizia & Madinah & Meena/Arafat \\
\hline Date of pilgrimage (day/month) & $8 / 9-24 / 9$ & $25 / 9-12 / 10$ & $29 / 8-20 / 9$ & NA \\
\hline Medical consultations, $n$ & 955 & 1511 & 602 & 712 \\
\hline Male, $n$ (\%) & $383(40.1)$ & $723(47.8)$ & $260(43.2)$ & NA \\
\hline Female, $n$ (\%) & $572(59.9)$ & $788(52.2)$ & $342(56.8)$ & NA \\
\hline Origin of pilgrims seeking medical consultation, $n(\%)$ & & & & $292(48.5)$ \\
\hline Western Cape & $332(34.8)$ & $510(33.8)$ & $5(0.8)$ & NA \\
\hline Eastern Cape & $9(0.9)$ & $21(1.4)$ & $180(29.9)$ & NA \\
\hline KwaZulu-Natal & $341(35.7)$ & $487(32.2)$ & $108(17.9)$ & NA \\
\hline Gauteng & $244(25.6)$ & $392(25.8)$ & $5(0.8)$ & NA \\
\hline Mpumalanga & $7(0.7)$ & $25(1.7)$ & $4(0.7)$ & NA \\
\hline Limpopo & $15(1.6)$ & $31(2.1)$ & $4(0.7)$ & NA \\
\hline Free State & $3(0.3)$ & $14(0.9)$ & $4(0.7)$ & NA \\
\hline North West & $4(0.4)$ & $22(1.5)$ & NA & NA \\
\hline North Cape & NA & $9(0.6)$ & NA \\
\hline
\end{tabular}

$\mathrm{NA}=$ not available. 
Table 2: Medical consultations among South African Hajj pilgrims $(n=2000)$ in 2014

\begin{tabular}{|l|c|c|c|}
\hline & \multicolumn{3}{|c|}{ Number of medical consultations, } \\
\hline Medical consultations & $\begin{array}{c}\text { Makkah } \\
n=955\end{array}$ & $\begin{array}{c}\text { Azizia } \\
n=1511\end{array}$ & $\begin{array}{c}\text { Madinah } \\
n=602\end{array}$ \\
\hline Respiratory & $63(6.6)$ & $225(14.9)$ & $50(8.3)$ \\
\hline Cardiovascular & $51(5.3)$ & $75(5.0)$ & $33(5.5)$ \\
\hline Gastroenterology & $6(0.6)$ & $25(1.7)$ & $9(1.5)$ \\
\hline ENT & $7(0.7)$ & $11(0.7)$ & $1(0.2)$ \\
\hline General surgery & $7(0.7)$ & $7(0.5)$ & 0 \\
\hline Orthopaedic & $18(1.9)$ & $9(0.6)$ & $7(1.2)$ \\
\hline Obstetrics/gynaecology & $15(1.6)$ & $23(1.5)$ & $10(1.7)$ \\
\hline Skin diseases & $2(0.2)$ & $17(1.1)$ & $10(1.7)$ \\
\hline Eye diseases & $15(1.6)$ & $15(1.0)$ & $10(1.7)$ \\
\hline Mouth and dental diseases & $21(2.2)$ & $9(0.6)$ & $2(0.3)$ \\
\hline General body pains & $298(31.2)$ & $502(33.2)$ & $183(30.4)$ \\
\hline $\begin{array}{l}\text { Dehydration/tiredness/ } \\
\text { nausea }\end{array}$ & $452(47.3)$ & $593(39.2)$ & $287(47.7)$ \\
\hline
\end{tabular}

ENT = ears, nose and throat.

Influenza is also fairly common during the Hajj. ${ }^{6-8}$ Circulating influenza strains were identified from 16 of 171 specimens collected during a surveillance study conducted in 2013 among South African pilgrims returning from the Hajj through Johannesburg OR Tambo International airport (Table 3). ${ }^{21}$ The vaccination status of these pilgrims was not reported. Prophylactic immunisation can reduce influenza disease during the Hajj; in 2010, the incidence of influenza-like illness among unvaccinated South African pilgrims was $13 \%$ compared with $8 \%$ among those vaccinated. ${ }^{22}$

\section{Streptococcus pneumoniae infection and transmission during the Hajj}

Streptococcus pneumoniae is one of the leading causes of pneumonia among pilgrims, $8,20,23$ with studies demonstrating increased transmission during the Hajj. ${ }^{24,25}$ Memish and colleagues investigated the aetiology of severe CAP in pilgrims hospitalised during the 2013 Hajj. ${ }^{26}$ Sputum samples collected from pilgrims diagnosed with severe CAP and bilateral pneumonia were assayed using real-time polymerase chain reaction (rt-

Table 3: Virus identification among a subset of South African pilgrims returning from the $2013 \mathrm{Hajj}^{21}$

\begin{tabular}{|l|c|c|c|c|} 
& \multicolumn{3}{|c|}{ South African pilgrims screened $(N=171)$} \\
\hline \multicolumn{1}{|c|}{ Virus } & $\begin{array}{c}\text { Oropharyngeal } \\
\text { swab } \\
(n=105)\end{array}$ & $\begin{array}{c}\text { Sputum } \\
(n=66)\end{array}$ & $\begin{array}{c}\text { Both } \\
(n=66)\end{array}$ & Total \\
\hline $\begin{array}{l}\text { Influenza A } \\
\text { H3N2 }\end{array}$ & 4 & 2 & 1 & 7 \\
\hline $\begin{array}{l}\text { Influenza A } \\
\text { H1N1 }\end{array}$ & 1 & 1 & 0 & 2 \\
\hline $\begin{array}{l}\text { Influenza B } \\
\text { Yamagata }\end{array}$ & 4 & 1 & 1 & 6 \\
\hline $\begin{array}{l}\text { Influenza A } \\
\text { H3N3 and } \\
\text { H1N1 }\end{array}$ & 1 & 0 & 0 & 1 \\
\hline $\begin{array}{l}\text { MERS-CoV } \\
\text { Total }\end{array}$ & 0 & & & 0 \\
\hline
\end{tabular}

MERS-CoV = Middle East respiratory syndrome coronavirus.
PCR) for MERS-CoV and a DNA multiplex array for other respiratory pathogens. MERS-CoV was not detected in any sample, while S. pneumoniae was identified in $53.8 \%$ of samples. ${ }^{26}$ In a large, prospective study of geographically diverse pilgrims with symptoms of respiratory infection during the 1991 and 1992 Hajj seasons, positive bacterial cultures were obtained in $30 \%$ of sputum and throat swab specimens; S. pneumoniae was identified in $4.8 \%$ and $12.3 \%$ of the culture positive samples from 1991 and 1992, respectively. ${ }^{8}$ The low percentage of positive cultures could be due to detection methods (i.e. bacterial culture versus PCR).

\section{Vaccination before the Hajj}

For the 2015 Hajj, the only compulsory vaccination for South African pilgrims $\geq 15$ years of age was that against meningococcal meningitis; children $<15$ years of age were required to be vaccinated against meningococcal meningitis and to be fully vaccinated in accordance with the South African Expanded Programme on Immunization. ${ }^{27}$ Although influenza vaccination was recommended for all pilgrims and pneumococcal vaccination was recommended for individuals $\geq 65$ years of age and those with certain underlying medical conditions, compliance was not mandatory for either vaccine. ${ }^{27}$ More recent guidelines, published by the Saudi Thoracic Society in 2016, recommend pneumococcal vaccination for all Hajj pilgrims $\geq 50$ years of age and for those $<50$ years with immunocompromising conditions. ${ }^{28}$ Though certain vaccinations are compulsory to attend the Hajj, not all pilgrims are compliant. ${ }^{29}$ In previous years, Saudi Arabia did not deny travel to pilgrims who were not vaccinated with meningococcal meningitis vaccine; instead, unvaccinated pilgrims were administered prophylactic antibiotics, or vaccinated, and allowed to complete the Hajj. Conversely, South African pilgrims who cannot verify that they have received the mandatory vaccinations are either denied a visa or policed at the airport and denied travel.

\section{Influenza vaccination}

Because influenza is a common cause of morbidity, mortality and hospitalisation during the Hajj, influenza vaccination is highly recommended by the South African Hajj and Umrah Council. $^{30}$ Every year the updated influenza vaccination formulation and general recommendations for vaccination are published in the South African Medical Journal during February or March. $^{31}$

\section{Pneumococcal vaccination}

For pneumococcal vaccination in adults, two types of vaccines are available, the 23-valent pneumococcal polysaccharide vaccine (PPSV23), which is licensed for use in individuals $\geq 2$ years of age, ${ }^{32}$ and the 13-valent pneumococcal conjugate vaccine (PCV13), which is indicated for use in individuals $\geq 6$ weeks of age. ${ }^{33}$ According to pneumococcal vaccination recommendations for the Hajj, PPSV23 can be used alone when cost and reimbursement are overriding issues. However, clinical studies suggest that PCV13 is more immunogenic than PPSV23 in children, immunocompromised adults and the elderly, ${ }^{34-36}$ and PCV13 has not been associated with hyporesponsiveness upon subsequent dosing. ${ }^{37-39}$ Moreover, the efficacy of PCV13 against invasive pneumococcal disease and all-cause pneumonia in the elderly, including those with underlying risk factors, has been demonstrated in adults $\geq 65$ years of age in the Community-Acquired Pneumonia immunisation Trial in Adults (CAPiTA) study. ${ }^{40}$ Together, this suggests that PCV13 should be the preferred vaccine in immunocompromised individuals and in the elderly. For those aged $\geq 65$ years who have never 
received PPSV23 or who have received PPSV23 before the age of 65 years and who are immunised with PCV13 in preparation for the Hajj, additional immunisation with PPSV23 at $\geq 1$ year after PCV13, and at least 5 years after the previous PPSV23 vaccination if it had been previously administered, could be used to provide a boost in immunity and continued protection against disease transmission within the community as well as from other pilgrims returning from subsequent Hajj and Umrah pilgrimages; a similar 'prime and boost' vaccination strategy has been used in the United States for those $\geq 65$ years of age. ${ }^{41}$ Furthermore, a similar 'prime boost' vaccination strategy could be considered for immunocompromised pilgrims aged 18 to 64 years and for those with sickle cell disease; however, the interval between PCV13 and PPSV23 vaccinations in this situation should be $\geq 8$ weeks; the interval of 5 years between PPSV23 vaccinations should remain the same. ${ }^{41}$ In both these situations, if PPSV 23 has been given in the past, the interval between that vaccination and the PCV13 vaccination should be at least one year.

\section{Influenza and Pneumococcal vaccination strategies for Hajj and Umrah pilgrims in South Africa}

Protection against concomitant infection with seasonal influenza and S. pneumoniae would be advantageous for pilgrims attending the Hajj and Umrah. This may be particularly relevant to South African pilgrims, since the entity 'influenza and pneumonia' is an important cause of mortality in South Africa, accounting for $5.2 \%$ of deaths in $2013 .{ }^{42}$ A number of studies support the combined use of prophylactic influenza and pneumococcal vaccines to reduce hospitalisation and mortality due to influenza and pneumonia. ${ }^{43,44}$ One literature review documented that combined use of PPSV23 and the seasonal influenza vaccine had additional clinical benefits compared with each vaccine administered alone. ${ }^{43}$ In another study, PPSV 23 given alone demonstrated considerable cross-protection against influenza-related diseases in adults and was effective as a single vaccination against influenza-associated morbidity. ${ }^{45}$ Similarly, the use of influenza vaccines and PCVs would be expected to reduce the burden of influenza and pneumonia among pilgrims travelling to the Hajj.

In summary, respiratory infections are a leading cause of illness during the Hajj, ${ }^{6-8}$ and pneumonia is among the leading causes of hospitalisation during the Hajj. ${ }^{9}$ Currently, vaccination against the influenza virus and $S$. pneumoniae is not mandatory. ${ }^{27}$ However, influenza vaccination is recommended for all Hajj pilgrims, and pneumococcal vaccination is recommended for pilgrims $\geq 50$ years of age and those $<50$ years with immunocompromising conditions. ${ }^{28}$ Influenza and pneumonia are leading causes of death in the general population of South Africa, and thus are of particular concern among South African pilgrims attending the Hajj, particularly due to the high percentage of pilgrims of advanced age and with comorbidities. ${ }^{42}$ Although the evidence base is primarily focused on Hajj, the recommendation may also be applicable to other mass gatherings such as Umrah.

Acknowledgements - The authors wish to thank the following Advisory Board members: Shakira Mahomed Cassim, Suleiman Abdulhay Kaka Hajee, David Hyams, Ebrahim Khan, Azwidihwi Nthangeni Manaka, and Abdool Kader Peer. Medical writing support was provided by Susan E. DeRocco, PhD, of Complete Healthcare Communications, LLC (West Chester, PA) and was funded by Pfizer Inc. The authors are responsible for the content of the manuscript and the decision to submit for publication.
Funding - This work was funded by Pfizer Inc.

Disclosure statement - Drs Gamil and Naidoo are employees of Pfizer Inc and may be eligible for stock and stock options. Dr Parker has received honoraria from Pfizer Inc, Sanofi, and GSK. Dr Hoosen has no competing interests to declare. Dr Feldman and Dr Khan have participated in advisory boards and speakers' bureaus for Pfizer Inc.

\section{References}

1. Gatrad AR, Sheikh A. Hajj: journey of a lifetime. BMJ. 2005;330:133-7.

2. Memish ZA, Zumla A, Alhakeem RF, et al. Hajj: infectious disease surveillance and control. Lancet. 2014;383:2073-82.

3. Parker S. The Hajj: a constant travel destination amidst changing times. South Afr J Epidemiol Infect. 2010;25:14-18.

4. Ahmed QA, Arabi YM, Memish ZA. Health risks at the Hajj. Lancet. 2006;367:1008-15.

5. Zombré $S$, Hacen $M-M$, Ouango $G$, et al. The outbreak of meningitis due to Neisseria meningitidis W135 in 2003 in Burkina Faso and the national response: main lessons learnt. Vaccine. 2007;25:A69-71.

6. Balkhy HH, Memish ZA, Bafaqeer $S$, et al. Influenza a common viral infection among Hajj pilgrims: time for routine surveillance and vaccination. J Travel Med. 2004;11:82-86.

7. Rashid H, Shafi S, Booy R, et al. Influenza and respiratory syncytial virus infections in British Hajj pilgrims. Emerg Health Threats J. 2008;1:e2.

8. El-Sheikh SM, El-Assouli SM, Mohammed KA, et al. Bacteria and viruses that cause respiratory tract infections during the pilgrimage (Haj) season in Makkah, Saudi Arabia. Trop Med Int Health. 1998;3:205-9.

9. Al-Ghamdi SM, Akbar HO, Qari YA, et al. Pattern of admission to hospitals during muslim pilgrimage (Hajj). Saudi Med J. 2003;24:1073-76.

10. van Ravenhorst MB, van der Klis FRM, van Rooijen DM, et al. Adolescent meningococcal serogroup $A, W$ and $Y$ immune responses following immunization with quadrivalent meningococcal $A, C, W$ and $Y$ conjugate vaccine: optimal age for vaccination. Vaccine. 2017;35:4753-60.

11. Recommended schedule for the Expanded Program on Immunization, Bahrain. [cited 2017 Jul 28]. Available from: https:// www.moh.gov.bh/Healthlnfo/lmmunizations?lang=en.

12. Karlamangla A, Tinetti M, Guralnik J, et al. Comorbidity in older adults: nosology of impairment, diseases, and conditions. J Gerontol A Biol Sci Med Sci. 2007;62:296-300.

13. File TM, Jr., Marrie TJ. Burden of community-acquired pneumonia in North American adults. Postgrad Med. 2010;122:130-41.

14. Torres A, Blasi F, Dartois $N$, et al. Which individuals are at increased risk of pneumococcal disease and why? Impact of COPD, asthma, smoking, diabetes, and/or chronic heart disease on communityacquired pneumonia and invasive pneumococcal disease: Table 1. Thorax. 2015;70:984-9.

15. Arab News. Half a million pilgrims received medical treatment during Haj. [cited 2016 Aug 17]. Available from: http://www.arabnews.com/ news/644031.

16. Mansouri F, Khorasani EN, Izadi M. Respiratory tract infection among Hajj pilgrims. Int J Travel Med Global Health. 2013;1:29-32.

17. Ibrahim N. Epidemiological pattern of diseases and risk behaviors of pilgrims attending Mina hospitals, Hajj 1427 h (2007g). J Egypt Public Health Assoc. 2008;83:15-33.

18. Mandourah Y, Al-Radi A, Ocheltree AH, et al. Clinical and temporal patterns of severe pneumonia causing critical illness during Hajj. BMC Infect Dis. 2012;12:117.

19. Al-Tawfiq JA, Memish ZA. The Hajj: updated health hazards and current recommendations for 2012. Euro Surveill. 2012;17:20295.

20. Baharoon S, Al-Jahdali $\mathrm{H}, \mathrm{Al}$ Hashmi J, et al. Severe sepsis and septic shock at the Hajj: etiologies and outcomes. Travel Med Infect Dis. 2009;7:247-52.

21. Parker S, Blumberg $L$, Takalani A. Respiratory pathogens surveillance in returning South African pilgrims after the 2013 Hajj: Johannesburg OR Tambo International Airport. Presented at: International Society of Travel Medicine; 2015 May 24-28; Quebec City, Canada.

22. Parker $\mathrm{S}$, Mendelson $\mathrm{M}$. The prevalence of upper respiratory tract infections and influenza like illness amongst South African Hajj 
pilgrims in 2010. Presented at: Conference of the International Society of Travel Medicine; 2012 May 8-12; Boston, MA.

23. Feldman C, Abdulkarim E, Alattar F, et al. Pneumococcal disease in the Arabian Gulf: recognizing the challenge and moving toward a solution. J Infect Public Health. 2013;6:401-9.

24. Memish ZA, Assiri A, Turkestani A, et al. Mass gathering and globalization of respiratory pathogens during the 2013 Hajj. Clin Microbiol Infect. 2015;21:e571-78.

25. Benkouiten S, Gautret P, Belhouchat K, et al. Comparison of nasal swabs with throat swabs for the detection of respiratory viruses by real-time reverse transcriptase PCR in adult Hajj pilgrims. J Infect. 2015;70:207-10.

26. Memish ZA, Almasri M, Turkestani A, et al. Etiology of severe community-acquired pneumonia during the 2013 Hajj-part of the MERSCoV surveillance program. Int J Infect Dis. 2014;25:186-90.

27. National Health Laboratory Service. Travel to Saudi Arabia during Hajj. [cited 2016 Aug 17]. Available from: http://www.nhls.ac.za/? page $=$ alerts\&id $=5 \&$ rid $=575$.

28. Al-Hajjaj MS, Alharbi NS, Zeitouni MO, et al. The Saudi Thoracic Society pneumococcal vaccination guidelines-2016. Ann Thorac Med. 2016;11:93-102.

29. Memish ZA, Assiri AM, Hussain R, et al. Detection of respiratory viruses among pilgrims in Saudi Arabia during the time of a declared influenza A(H1N1) pandemic. J Travel Med. 2012;19:15-21.

30. South African Hajj and Umrah Council. Welcome to the South African Hajj Registry for 1439. [cited 2018 May 11]. Available from: https:// registry.sahuc.org.za/.

31. Walaza S, Cohen C. Recommendations pertaining to the use of influenza vaccines and influenza antiviral drugs, 2016. S Afr Med J. 2016;106:251-3.

32. Pneumovax $23^{\oplus}$ (pneumococcal vaccine polyvalent). Full Prescribing Information. Whitehouse Station, NJ: Merck \& Co., Inc.; 2015.

33. Prevenar $13^{\otimes}$ (pneumococcal 13-valent conjugate vaccine [diphtheria $\mathrm{CRM}_{197}$ protein]). Sandon, South Africa: Pfizer Inc.; 2015.

34. Ridda I, Musher DM. Is there a potential role for protein-conjugate pneumococcal vaccine in older adults? Australas Med J. 2012;5:231-5.

35. Moberley S, Holden J, Tatham DP, et al. Vaccines for preventing pneumococcal infection in adults. Cochrane Database Syst Rev. 2013;1: CD000422.
36. Fedson DS, Nicolas-Spony L, Klemets $P$, et al. Pneumococcal polysaccharide vaccination for adults: new perspectives for Europe. Expert Rev Vaccines. 2011;10:1143-67.

37. O'Brien KL, Millar EV, Zell ER, et al. Effect of pneumococcal conjugate vaccine on nasopharyngeal colonization among immunized and unimmunized children in a community-randomized trial. J Infect Dis. 2007;196:1211-20.

38. de Roux A, Schmöle-Thoma B, Siber GR, et al. Comparison of pneumococcal conjugate polysaccharide and free polysaccharide vaccines in elderly adults: conjugate vaccine elicits improved antibacterial immune responses and immunological memory. Clin Infect Dis. 2008;46:1015-23.

39. Jackson LA, Gurtman A, van Cleeff $M$, et al. Influence of initial vaccination with 13-valent pneumococcal conjugate vaccine or 23-valent pneumococcal polysaccharide vaccine on anti-pneumococcal responses following subsequent pneumococcal vaccination in adults 50 years and older. Vaccine. 2013;31:3594-602.

40. Bonten MJM, Huijts SM, Bolkenbaas M, et al. Polysaccharide conjugate vaccine against pneumococcal pneumonia in Adults. N Engl J Med. 2015;372:1114-25.

41. Kobayashi M, Bennett NM, Gierke R, et al. Intervals between PCV13 and PPSV23 vaccines: recommendations of the Advisory Committee on Immunization Practices (ACIP). MMWR Morb Mortal Wkly Rep. 2015;64:944-47.

42. Statistics South Africa. Causes of death 2013. [cited 2016 Aug 17]. Available from: http://www.statssa.gov.za/?page_id=737\&id=3. \&paged=2. Accessed August 17, 2016.

43. Gilchrist SAN, Nanni A, Levine O. Benefits and effectiveness of admin istering pneumococcal polysaccharide vaccine with seasonal influenza vaccine: an approach for policymakers. Am J Public Health. 2012;102:596-605.

44. Christenson $B$, Hedlund J, Lundbergh $P$, et al. Additive preventive effect of influenza and pneumococcal vaccines in elderly persons. Eur Respir J. 2004;23:363-68.

45. Blay A, Bessler $H$, Lahad A, et al. Does pneumococcal vaccine reduce influenza morbidity in humans? Vaccine. 2007;25:1071-75.

Received: 18-12-2017 Accepted: 1-06-2018 